\title{
INTERVENÇÕES FISIOTERAPÊUTICAS NO AMBIENTE OCUPACIONAL: UMA REVISÃO SISTEMÁTICA DOS ESTUDOS LISTADOS NA BASE DE DADOS PEDRO
}

\author{
AUTOR: BRENDA SANTANA ALMEIDA \\ CO-AUTOR: ROSIMEIRE SIMPRINI PADULA \\ CO-AUTOR: LUCIVANIA CORDEIRO SILVA \\ CO-AUTOR/ORIENTADOR: MARIA LUIZA CAIRES COMPER
}

\begin{abstract}
Resumo: O fisioterapeuta especialista em saúde ocupacional pode atuar em uma gama de contextos de atividade, utilizando-se de diferentes técnicas e métodos. Entretanto, sua atuação se concentra, principalmente, na análise ergonômica do trabalho, devido os múltiplos componentes a serem considerados na decisão da melhor intervenção para o ambiente ocupacional. Desta forma, torna-se relevante a procura das melhores evidências científicas para medir os efeitos de determinada intervenção em diferentes contextos ocupacionais. Assim, o objetivo desta revisão é identificar, analisar e sintetizar evidências científicas sobre intervenções que podem ser realizadas por fisioterapeutas no ambiente ocupacional. Trata-se de uma revisão sistemática da literatura. A pesquisa foi realizada na Physiotherapy Evidence Database (PEDro), por ser uma base de dados gratuita e com a mais completa indexação de estudos específicos para fisioterapia. Utilizou-se o descritor "workplace", selecionando no campo de buscas as opções "ergonomics", "occupational health" e "clinical trials". Foram incluídos todos os artigos de ensaio clínico randomizado (ECR) com intervenções no ambiente de trabalho realizadas por fisioterapeutas, com pontuação na escala Pedro $>6,0$ pontos, indexados até julho de 2020. A qualidade metodológica dos ECRs foi atribuída conforme a classificação da escala PEDro, indicada na base de dados. Dois avaliadores independentes participaram da análise dos artigos encontrados e, em caso de desacordo, consultaram um terceiro. Os dados foram extraídos para uma planilha Excel e classificados de acordo com as atribuições do fisioterapeuta do trabalho, descritas na Resolução no. 465/2016. Ao final, foram incluídos 75 estudos, publicados entre os anos de 1994 e 2020. A média de pontuação na escala PEDro foi $6,7 \pm 0,84$. A população dos estudos incluiu, principalmente, trabalhadores de escritório (40\%) e a intervenção mais comum foi programa de exercício físico $(74,7 \%)$. Resultados positivos foram observados quando o treinamento físico incluiu algum tipo de resistência ao aumento da intensidade dos movimentos (com halteres ou faixas elásticas), supervisionado e com mais de 10 semanas. Intervenções ergonômicas foram pouco descritas (6,7\%), apresentando resultados positivos quando envolveram ergonomia participativa. 0 estudo demonstrou que existem evidências razoáveis para intervenções baseadas em exercícios, e um baixo nível de evidência para intervenções ergonômicas e educativas na PEDro.
\end{abstract}

Palavras-chave: Saúde do trabalhador, Tomada de Decisão, Prática Baseada em Evidências. 